\title{
ASSESSMENT OF KNOWLEDGE, ATTITUDE AND PRACTICES OF COVID-19 AMONG TEACHERS AND STUDENTS OF KARACHI, LAHORE AND ISLAMABAD
}

\author{
Tanzeela Yaqoob \\ Lecturer \\ Department of Statistics, University of Karachi \\ Sindh, Pakistan \\ Email: tanzeela@uok.edu.pk \\ Imran Hameed Khaliq \\ Lecturer \\ Department of Public Health, University of Health Sciences, Lahore, \\ Punjab, Pakistan \\ Email: imranham90@gmail.com \\ Faraz Ahmed Farooqi \\ Lecturer \\ Department of Academic Affairs, Imam Abdulrahman Bin Faisal University, \\ Dammam, KSA \\ Email: fafarooqi@iau.edu.sa
}

\begin{abstract}
The pandemic of Covid-19 has shaken the world tremendously. Globally, the preventive measures are applied which meagerly enabled the health systems of various countries to fight against the pandemic as the clinical trials of vaccination and quest of effective therapeutic treatment is still in progress. Developing countries like Pakistan are also going through the difficult times amid Covid-19 pandemic. Therefore, essential preventive measures are crucial to control the situation among general population. This cross-sectional study aims to investigate the knowledge, attitude and practices (KAP) of Pakistanis residents towards the preventive measures to fight against Covid-19 global pandemic and to explore the relationship of KAP scores related to Covid-19 with demographic characteristics of teachers and students. The complete data was retrieved from 849 respondents out of 1000 questionnaires living in three different cities of Pakistan namely Karachi, Lahore and Islamabad. The convenient sampling procedure was adopted as survey was taken during the month of April and May 2020, when complete lock down was observed in Pakistan. To access the significant differences among demographic characteristics of an individual
\end{abstract}


independent t-test, Chi-square test and ANOVA was applied. Canonical correlation analysis was employed to ascertain the relationship between KAP scores and demographic variables. Results showed that out of 849 respondents, $89 \%$ has good knowledge, 90\% scored well in attitude and 75\% of teachers and students are sound practicing in order to save themselves from Covid-19.

\section{KEYWORDS}

Canonical correlations, Covid-19, KAP, Lock down

\section{INTRODUCTION}

The outbreak of Covid-19 carries the challenge around the globe. The last month of 2019 brings the news of outbreak of coronavirus in the Wuhan city of China and the situation getting worse when it quickly spread in almost all over the world within two months (Dang (2020). On January 30, 2020 World Health Organization announced worldwide sixth public health emergency (Bilgin et al. (2020)) and stated it pandemic on March 11, 2020. Around the globe the USA has reported highest number of deaths followed by Italy, Spain and UK etc. however the USA observing a health emergency call from January 31, 2020 with the first reported case on January 20, 2020. According to the World Bank statistics above 40 million cases and 1.1million deaths were confirmed worldwide by October 20, 2020.

Likewise other countries, Pakistan also not escaped from this virus. Fortunately our country was affected late as the first confirmed case of COVID-19 declared by the ministry of Pakistan was reported at February 26, 2020 in the Karachi city with travelling history from Iran while by Efrani (2020) the first positive case in Iran was reported on February 19, 2020.The sudden eruption of Covid-19 in Pakistan shakes the fundamentals of our country due to the unstable health infrastructure as the reported cases crossed the digit of 7 thousand in the mid-April, 2020 declared by the officials of government. The necessary steps has been taken individually or collectively to avoid any medical emergency in the country but only few days later on March 20, 2020 the administration get locked the unnecessary movements of people and business at various parts of the country. According to Waris et al. (2020) traveling from cross borders area is one of the reasons of transmission of coronavirus in Pakistan as its border is surrounded by highly affected countries like Iran, Italy and China.

To successfully pass the battle against pandemics the attitudes, behavior, Knowledge and practices of common people play an important role. In this context Hasan et al (2018) did a cross-sectional study to access the knowledge, attitude and usual practices related to swine flu among dental and medical students. They find that many of the students are aware about the swine flu but they didn't follow the precautionary measures in their routine life. The study only shows the perspective of 613 dental and 
medical students of Karachi city. The battle of Coronavirus is still going on all over the world. Since the virus is emerging and affecting thousands of people on daily basis the exact symptoms, preventions and cure are still in process. Moreover no authentic and particular medicine against the coronavirus is available as explained by Wang and Zang (2020). According to World Health Organization (WHO) the human interaction should be avoid for reducing the transmission of the infection among close contacts, health workers and also on international level. Similarly avoid transmission from animal source, thoroughly addressing the unknowns whom are crucial, getting them aware of more curable options, knowledge about the extension and transmission of infection, also acceleration of diagnosis and vaccines should be focused, authentically providing awareness to the people about critical risks and also countering the panic situations caused by misinformation are few of the strategies mentioned by WHO.

With respect to the preventive measures taken by the individuals against Covid-19 Azlan et al. (2020), Paul et al. (200), Erfani et al. (2020) and Hayat et al. (2020) explores the dimension of Knowledge, awareness and practice capabilities of Malaysian, Bangladeshis, Iranian and Pakistanis respectively. In the early studies related to Covid-19 Syed and Sibgatullah (2020) estimates the total number of cases in Pakistan will rise by the end week of June 2020. They used SIR modelling approach and emphasized to follow the defensive methods against Covid-19 otherwise bulk of population in Pakistan can be affected by the virus. With the help of the data comprising of 33 days they showed an increasing trend in the number of cases in Pakistan. In such situation the knowledge about the virus to the common man is seems important. The studies related to KAP is not new for infectious diseases as researchers thought that awareness related to any disease/virus can help people for prevention. The knowledge about any disease/virus must reflect in the attitudes of an individual as shown by Zhong et al. (2020) that in China many women having good socioeconomic positions have enough knowledge about Covid-19 along with proper prevention practices. They did a cross-sectional survey related to KAP concerning Coronavirus in the Hubei province of China and find almost $90 \%$ of the respondents have correct knowledge and applying precautionary measures against Covid-19. Related to the KAP Almutairi et al (2015) conducted survey among 1147 residents of Riyadh, Saudi Arabia about the MERS-CoV epidemic and showed that most of the people are aware about the virus and adopt necessary precautions to protect themselves from MERS$\mathrm{CoV}$. The positive cases of MERS-CoV was reported in different Middle east countries including Saudi Arabia in 2014 and now a days like whole world they are also facing the challenge of Covid-19 having complete lockdown in the country. The medical representatives of Pakistan are advising continuously to be at home and maintain social distancing to reduce the attack of virus. The awareness programs through Media (TV), print media and social networks are playing positive role to increase the knowledge related to Covid-19 among the people. Among different preventive measures social 
distancing is essential which only make possible through smart strategies employed by the government.

The aim of the study is to observe the awareness and knowledge about the corona virus among teachers and students in three different cities of Pakistan. According to the KAP theory people's knowledge, attitude and practices towards infectious disease can help to manage or deal effectively and inhibit the spread of disease. Few studies like Ajilore et al. (2015) emphasize that the assurance of achievement against the epidemic KAP of nation play an effective role.

The knowledge provides awareness and due to awareness people practices the precautions in their daily life. The demographics of the person play an important role regarding the assessment of their knowledge and practices. Unlike Hayat et al (2020) this study collected the sample from three major dense populated cities of Pakistan and also asked questions related to the preventive steps taken at state level. Furthermore this study observe the relationship between knowledge, attitude and practice score with different demographic variables by employing multivariate technique of canonical correlation analysis developed by Hotelling (1936). To fight against the pandemic the contribution of people takes an important part along with the actions and steps taken at state level.

\section{RESEARCH OBJECTIVE}

1. To access the knowledge of the people particularly the teachers and students of Pakistan about coronavirus by sophisticated statistical approach of canonical correlations.

\section{RESEARCH HYPOTHESIS}

1. Is there a significant difference among the variables defined on two (more than two) groups.

2. Is KAP score and demographic variables are correlated with each other on not?

\section{RESEARCH METHODOLOGY}

This cross-section survey has been conducted between the month of April and May 2020 at three different cities of Pakistan Karachi, Lahore and Islamabad. These days the number of positive cases was mainly reported from Sindh and Punjab province thus these three cities were considered for taking responses. Due to the lock down situation in Pakistan, the responses have been taken online through emails and WhatsApp by using the google doc questionnaire.

\section{Study instrument}


The 26-item closed ended questionnaire was developed by following the strategies proposed in the literature of Zhong et al. (2020) under the team of authors from various disciplines. The validity of questionnaire was checked by sending it to two senior general physicians of Karachi city and asked them to provide their opinion regarding various features of the instrument related to ease and dependence. Furthermore the understanding level of questionnaire was accessed by conducting the pilot survey with 10 individuals. The questionnaire was divided into three sections. In the first section six items were employed to access the demographic features of an individual. The age were asked (in intervals of years), gender, Residential city (Karachi, Lahore and Islamabad), marital status (Single, married and Divorce/Widow), Employment status (Government Employee, Private Employee, Businessman, Retired, Unemployed, Housewife and student) and education level were asked by (primary, secondary, Intermediate, Bachelors, masters and Post graduate).

For the assessment of knowledge of an individual eight items were used. The first three closed ended questions were asked like what are the causes of Covid-19 (Weak Immune System, Inherited Disease, A Virus and The disease is infectious and can spread from person to person), how does it transmits (Through droplets after sneezing, Through touching or shaking hands with infected person and Through objects used by an infected person) and what are the sign/symptoms of Covid-19(Fever, Dry Cough, Fatigue, Diarrhea and Shortness of Breath). Rests of the items were asked as dichotomous variable i.e. Yes/No. Is covid-19 a respiratory disease, is it curable, whether it leads to death, is it transmits from animals to humans and it can affect humans more than once. Self-practices of an individual were mediated by 5 different constructs. What is the best prevention from Covid-19 (stay at home, going outside with mask and gloves), What are the preventions you personally adopt after getting to know about Covid-19 (Often wash hands with soap, Avoid touching eyes, nose and mouth, Cover face with mask, Wear gloves, Cover your face with mask and wear gloves, Cover nose and mouth with a tissue/elbow while coughing/sneezing), How do you think people can act properly on the orders/advices are being told by the government(By spreading word through SMS, Door to door awareness, By taking strict action against law breakers, All) were the three and remaining two were dichotomous variable consist of: Do you consume more nutritional diet nowadays and Nowadays, do you spend more time in religious activities/obligations. The attitudes were judged by asking three questions on binary scale that is Do you think complete lock down is the only solution for the removal of Covid-19, Do you think our government are taking right steps to prevent our nation from Covid-19 and Do you think Pakistan can successfully get rid of Covid-19.

The knowledge, attitude and practice scores of the respondents were further classified as good and poor by allocating single weight to right response. Knowledge score having less than and equal to 6 considered as poor and greater than equals to 17 as 
good, attitude score greater than 1 measured as good while practice score more than 6 taken as good score.

\section{Statistical Methodology}

The statistical analysis on the gathered data comprises of counts of correct classified responses, descriptive statistics of demographic variables and knowledge, attitude and practice scores of an individual. To compare the knowledge, attitude and practices of an individual independent t-test, One-way Analysis of Variance (ANOVA) and Chisquare test of independence has been applied according to the nature of the variable. The independent t-test allows us to test the significant difference among the variables defined on two groups while One-way Anova allows the researcher to make inference about target variable with more than two groups and chi-square test is suitable for categorical responses. These tests served as the first stage of our analysis.

At the second stage the canonical correlation analysis (CCA) developed by Hotelling (1936) was employed to explore the relationship between three KAP scores and demographic variables. The procedure of CCA can be used as an extension of multiple correlations as described in Rencher (2002). In Rencher (2002) the technique of CCA allows us to identify the relationship of more than one dependent variable with a list of independent variables, assuming two sets of variables as $y^{\prime}=\left(y_{1}, y_{2}, \ldots, y_{r}\right)$ and $x^{\prime}=\left(x_{1}, x_{2}, \ldots ., x_{s}\right)$. In our study we take KAP scores as a dependent set of variables while demographic variables as an independent set of variables.

This multivariate technique estimates the parameters for the set of response variables as well as a set of covariates. Likewise simple linear regression the previously estimated parameters make a way to discover the linear combination concerning the variable of interest named as canonical variables. The canonical variable/function is orthogonal to every other variable/function, due to this collective set of designed predictor variables and principle variables would be uncorrelated with the other functions response and independent sets (Sherry and Henson (2015)). Similarly, the associations among the canonical variables are termed as canonical correlations. The vectors of coefficient ' $c$ ' and' is obtained through the first canonical correlation by maximizing the correlation among the linear combination of $c^{\prime} x$ and $d^{\prime} y$, similarly by holding the assumption of zero links to the first variate a subsequent couple of canonical variates are found up until min $(r, s)$. Theses canonical correlations can be accessed through different statistical tests named as Wilks' Lambda, Lawley-Hotelling statistics, Roy's and Pillai's test. The significance of canonical correlations through Fapproximation was calculated by Rencher (2002) and leads us to identify the number of canonical correlations inferred to loadings associated with variables under study and proposed linear combination. These loadings seem to be important while exploring the link between the set of predictors and covariates and its coefficients are showing 
possessed value, more than 0.3 are found to be significant. For the mathematical formulation of CCA see Rencher and Christensen (2012). In the study, all analysis was performed on the statistical package for social sciences (SPSS) version 21.0.the correlation between them as in multiple regression (Courville, 2001). According to Lambert and Durand (1975) loadings of associated variable

\section{Ethical approval}

This study was approved by Hussain college of Health Sciences, Lahore Pakistan HMH/2020/ERC/1197

\section{RESULTS \& DISCUSSION}

The 0.720 value of Cronbach's alpha provides us the acceptable reliability of the survey. Out of 849 respondents $372(44 \%)$ were male and $477(56 \%)$ were female. The complete survey has been filled by 603 respondents from Karachi, 153 from Lahore and 94 were from Islamabad. The majority of responses (as students are taking into consideration) were from the age ranging from 18-24 years followed by $25-30$ years respectively. Regarding to the employment status 289 respondents is privately employed (Private education institutes) followed by 284 unemployed (during Covid19 time period) individuals. Furthermore 56 respondent holds Postgraduate degree, 362 respondents hold master's degree, 341 bachelors and 90 respondents were intermediate. The average knowledge score was found to be 11.80 (standard deviation 2.61, range 3-17), average attitude score was 2.517 (standard deviation 0.712 , range $0-3$ ) while mean practice score was 8.024 (standard deviation 2.07, range 2-12). The highest score is predicting the good understanding of KAP towards COVID-19. The summary statistics of respondents by demographic variables are described in Table 1. P-values are also evaluated by employing independent t-test, one way-Anova and chi-square test of independence are reported in Table 1 indicating that KAP score are significantly differ across all demographic variables.

Table 1: $\quad$ Summary statistics of respondents by demographic variables with KAP score of COVID-19

\begin{tabular}{|c|c|c|c|c|c|c|}
\hline $\begin{array}{c}\text { Demogr } \\
\text { aphic } \\
\text { variables }\end{array}$ & & $\mathbf{N}$ & $\begin{array}{c}\text { Knowledge } \\
\text { score } \\
(\bar{x} \pm \sigma)\end{array}$ & $\begin{array}{c}\text { Attitude } \\
\text { score } \\
(\bar{x} \pm \sigma)\end{array}$ & $\begin{array}{l}\text { Practice } \\
\text { score } \\
(\bar{x} \pm \sigma)\end{array}$ & $\begin{array}{c}P- \\
\text { value } \\
t / F / \\
\chi^{2}\end{array}$ \\
\hline \multirow[t]{2}{*}{ Gender } & Male & 372 & $12.09+2.82$ & $2.45+0.73$ & $8.19+2.13$ & \multirow{2}{*}{0.006} \\
\hline & Female & 477 & $11.59+2.43$ & $2.57+0.69$ & $7.9+2.02$ & \\
\hline \multirow[t]{2}{*}{ Age } & $\begin{array}{l}\text { Less than } 18 \\
\text { years }\end{array}$ & 17 & $10.24+2.41$ & $2.2+0.97$ & $6.88+1.69$ & \multirow{2}{*}{$\begin{array}{c}<0.0 \\
01\end{array}$} \\
\hline & 18 to 24 years & 325 & $10.93+2,39$ & $2.52+0.68$ & $7.53+1,94$ & \\
\hline
\end{tabular}




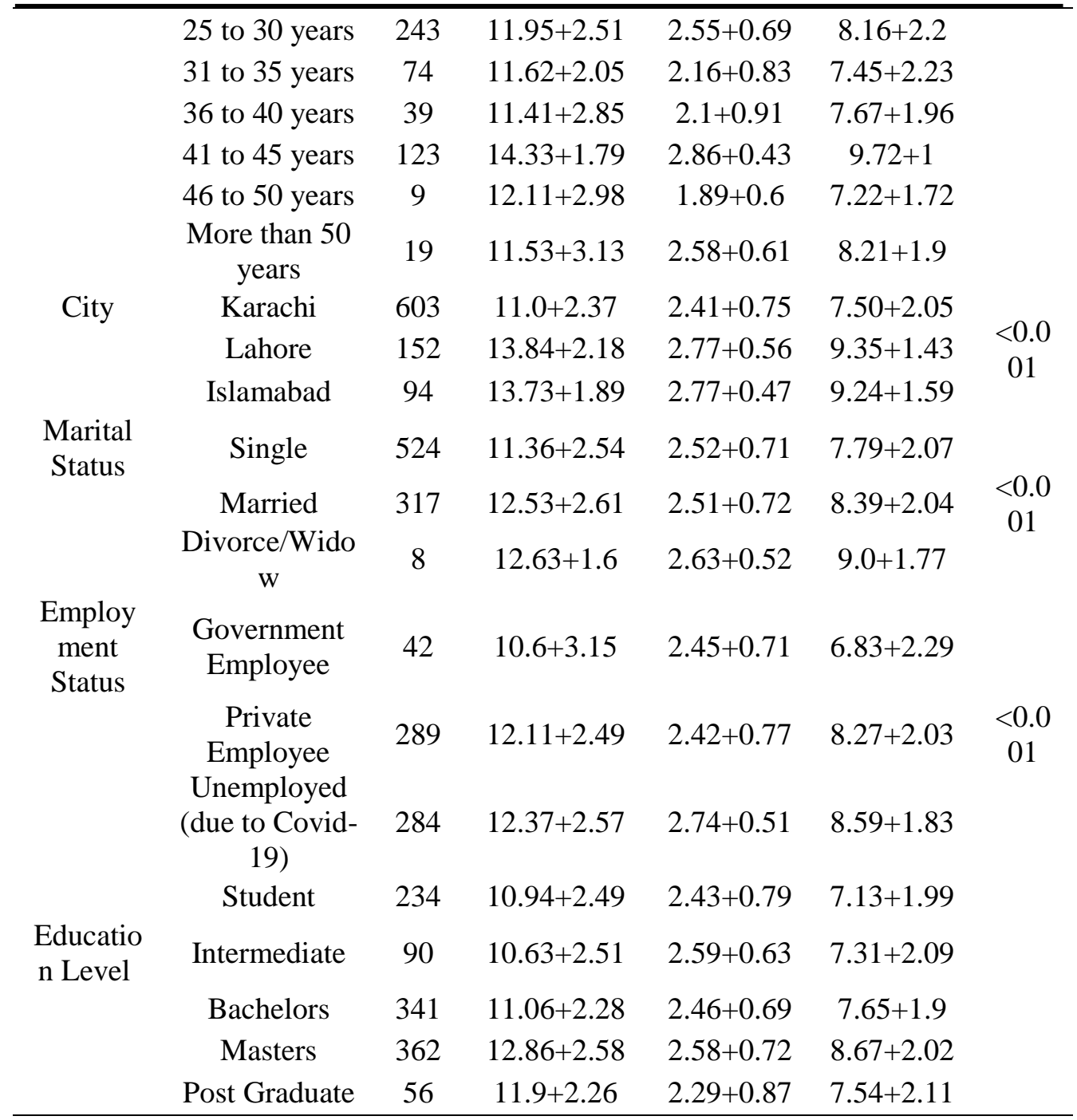

The robustness of full model is evidenced through various multivariate tests presented in Table 2. The P-values are found to be significant at 5\% level of significance and supports the existence of relationship between KAP score and demographic variables.

Table 2: $\quad$ Multivariate tests

\begin{tabular}{cccccc}
\hline $\begin{array}{c}\text { Test } \\
\text { Name }\end{array}$ & Value & Approx. F & $\begin{array}{c}\text { Hypothesis } \\
\text { DF }\end{array}$ & $\begin{array}{c}\text { Error } \\
\text { DF }\end{array}$ & $\begin{array}{c}\text { Prob>F- } \\
\text { statistic }\end{array}$ \\
\hline Pillais & 0.32361 & 16.96808 & 18 & 2526 & 0.001 \\
\hline
\end{tabular}


PJER, Vol 4, Issue 1 (2021)

Assessment of knowledge...

\begin{tabular}{cccccc} 
Hotellings & 0.44285 & 20.63363 & 18 & 2516 & 0.001 \\
Wilks & 0.68625 & 18.79739 & 18 & 2376.36 & 0.001 \\
Roys & 0.28978 & & & & \\
\hline
\end{tabular}

The three canonical correlations were rescued through the analysis as we have minimum three variables in response set of variables (Table 3). These canonical correlation access the power of association among the linear combination of Knowledge, attitude and practices score with demographics of an individual. For instance the canonical correlation for first variate exceeds 0.5 i.e. 0.5381 indicating that $28.97 \%$ common variance in KAP score has been explained by the demographic variate. Likewise the second canonical correlation is showing $3.12 \%$ of common variance in KAP score has been explained by the demographic variate .However the joint significance of succeeding canonical correlations with F-test displaying two significant variates. Thus the linear hybrid of the KAP score related to Covid-19 is significantly associated to the demographics of an individual.

Table 3: $\quad$ Canonical correlations and their significance

\begin{tabular}{ccccc}
\hline $\begin{array}{c}\text { Canonical } \\
\text { Variates } \\
\text { number }\end{array}$ & $\begin{array}{c}\text { Canonical } \\
\text { correlation }\end{array}$ & $\boldsymbol{R}_{\boldsymbol{c}}^{\mathbf{2}(\boldsymbol{\%})}$ & $\begin{array}{c}\text { Wilks Lambda } \\
\text { (F-statistic) }\end{array}$ & $\begin{array}{c}\text { P>F- } \\
\text { Statistic }\end{array}$ \\
\hline 1 & 0.53831 & $0.28978(28.97)$ & $0.68625(18.797)$ & 0.000 \\
2 & 0.17666 & $0.03121(3.12)$ & $0.96625(2.912)$ & 0.001 \\
3 & 0.05123 & $0.00262(0.26)$ & $0.99738(0.553)$ & 0.696 \\
\hline
\end{tabular}

After observing the significant canonical variates we need to discuss the structural loadings. These loadings corresponding to significant canonical variates identify the important variables utilize for the prediction of KAP score towards demographic characteristics of an individual (Table 4).

Table 4: $\quad$ Loadings of extracted significant canonical correlations

\begin{tabular}{ccc}
\hline Response set & Loadings of CV-I & Loadings of CV-II \\
\hline Knowledge score & 0.94641 & -0.12041 \\
Attitude score & 0.36931 & 0.92731 \\
Practice score & 0.73898 & 0.00145 \\
Covariates & & \\
Gender & -0.16098 & 0.67404 \\
Marital status & 0.39173 & -0.47398 \\
City & 0.8859 & 0.18771 \\
Age & 0.64188 & -0.40516 \\
\hline
\end{tabular}




\begin{tabular}{ccc}
\hline Employment & -0.11715 & 0.54867 \\
Education & 0.55287 & -0.62991 \\
\hline
\end{tabular}

The loadings of first canonical variate for marital status, city, age and education level of a person are found to be significant with more than 0.3 value. Moreover gender and employment status are not showing significant effect on knowledge, attitude and practices of a person. The loadings related to first canonical covariate for KAP score towards demographics of a person are appeared to be high. The Knowledge score is highly positive related to marital status, city, age and educational level of a person. It indicates that knowledge towards Covid-19 depends upon the reason that person is married or unmarried, the city where he/she lives, his/her age and education level.

After the knowledge score the practice score of a person demonstrating positive association with marital status, city, age and educational level of a person. It reveals that knowledge of a person toward Covid-19 reflects in the practices of teachers and students of Karachi, Lahore and Islamabad. Furthermore the first canonical variate explains $52.6 \%$ (average of squared sum of loadings) variation of the original variables for set of response variable and $28.25 \%$ (average of squared sum of loadings) variance for set of covariates.

The second canonical covariate is showing significant loadings for covariates except city of a person. It shows that instead of city other demographics affect the person's KAP score related to COVID-19. Similarly second canonical covariate is showing negative association between knowledge score and age, marital status and education of a person while attitude score is highly correlated to gender, city and employment status. This relationship is indicating that knowledge score decreases as age and education level increases and vice-versa. Thus second canonical covariate creates some misleads towards the relationship.

In addition of it the second canonical variate explains $29.14 \%$ (average of squared sum of loadings) variation of the original variables for set of response variable and $26.27 \%$ (average of squared sum of loadings) variance for set of covariates. Overall the variation explained by both the canonical covariates indicates that demographics of a person lead towards better KAP score related to Covid-19. It has also been observed through Figure 1 that out of 849 respondents $89 \%$ has good knowledge which is somehow in line with the recent study of Hayat et al. (2020), 90\% scored well in attitude and $75 \%$ people are sound practicing in order to save themselves from Covid19. 


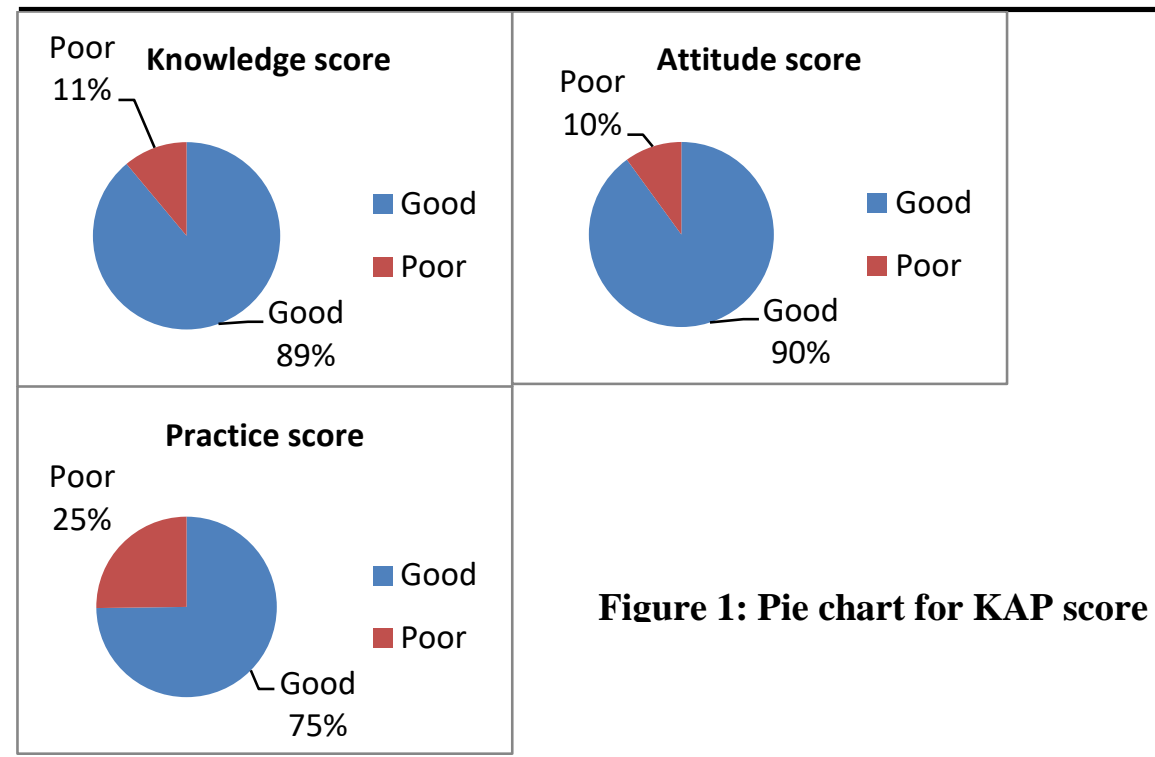

Concerning to the sources of learning related to coronavirus Figure 2 is depicting those $49.47 \%$ individuals are using social networks followed by $28 \%$ utilizing Media (TV) to increase their knowledge. Figure 2 is also portraying that 533 out of 849 respondents are well-thought-out that their health status is good.

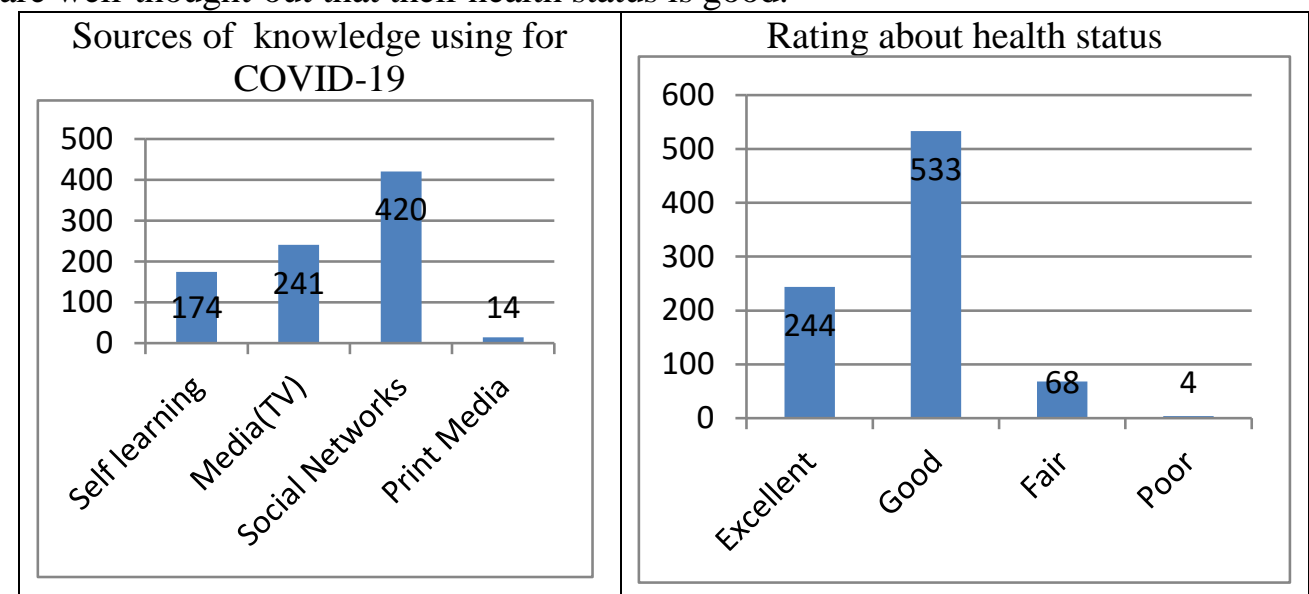

Figure 2: Sources of knowledge using for Covid-19 and health status rating Regarding to the knowledge about the causes of Covid-19, 86.7\% respondents knows it very well that disease is infectious and can spread from people to people, $71.5 \%$ knows that it is a virus while $69.5 \%$ says that individuals having weak immune system can infected through it easily. $90.9 \%$ respondents are sure about the transmission of coronavirus can be done through touching or shaking hands with infected persons 
while $88.9 \%$ of the individuals think that it is a curable virus. Related to the knowledge about signs/symptoms related to coronavirus 540 residents from Karachi, 90 respondents out of 94 and 148 from Lahore knows that fever is the initial sign of having the virus in body. Out of the 341 respondents 300 people having bachelor's degree and 33 out of 41 postgraduate holder thinks that Covid-19 is curable.

The real cause of spreading coronavirus is still in progress while Shereen et al (2020) provides an evidence that it blowouts from Hunan seafood market at Wuhan city of China and it quickly affect 109 countries of the world. Pakistan is now a days facing economic and social challenges due to the outbreak of Coronavirus. It has been observed that average knowledge and practice score of male is higher than the female. The awareness of diseases among teachers and students is well enough to educate the maximum people around them as the real cause and symptoms are still innovative in nature.

This study has several limitations. The sample of 894 is not an effective representation of more than 200 million of the population; therefore the results cannot be generalized. More over the affordability and access of internet in Pakistan for middle and lower middle community is vulnerable thus our study only approach those subjects who possess online facility. Secondly this study provides statistical evidence related to the demographic characteristics and KAP scores that would be beneficial for government of Pakistan to build understanding about the knowledge, attitude and practices of common man. In the recent study of Noorbhai (2020) mathematical model is proposed in terms of risk/ratio criteria which will be helpful to reopening the economies all around the globe.

\section{CONCLUSION AND RECOMMENDATIONS}

This study attempts to find that whether the knowledge of teachers and students living in Karachi, Lahore and Islamabad related to the corona virus is enough to successfully pass the battle against the Covid-19 or not. The study comprises total of 849 samples out of which $372(43.8 \%)$ were male and $477(56.2 \%)$ were females. The cross section study was taken online from the respondents belongs to Karachi (603), Lahore (152) and Islamabad (94). $49.5 \%$ people from the overall sample are using social networks followed by $28.4 \%$ using Media (TV) to raise their knowledge related to Covid-19. $71 \%$ of the people are showing concern toward their health and consume more nutrition's diet along with $79.9 \%$ individuals are spending their time in religious activities/obligations. The study utilizes the multivariate technique of canonical correlation to identify the association between KAP score and demographic characteristics of sample and showed that knowledge related to Covid-19 is reflecting into the practices and attitudes of a common man. Along with this $95.6 \%$ favors to stay at home during lockdown while $92.6 \%$ people think that government should take strict 
action against those who break the law during the lockdown. Nobody knows that how long the virus will take to get rid from the world, only preventive measures can save the precious lives. To control the situation one should follow the suggestions provided by WHO and neighbor country China who successfully win the war against the virus. The statistical evidence linked to the sample taken by the study shows the positive attitude towards the steps taken by the government and people are trying to adopt maximum preventive measures to keep social distancing. People are not only educating themselves to face the virus but they also prepare themselves by taking good care of their health and spending more time to religious activities/obligations. Lock down may be the temporary solution to save precious lives from this pandemic but the need of opening the education and business activities in the country is rising. This study can provide a guideline to the policy makers to shape their strategies to regulate the activities in the country according to the awareness level of the individual. For future strategies more sophisticated statistical technique may apply to explore more dimensions of knowledge scores towardCovid-19.

\section{REFERENCES}

Ajilore K., Atakiti I., Onyenankey, K. (2017). College students' knowledge, attitudes and adherence to public service announcements on Ebola in Nigeria: Suggestions for improving future Ebola prevention education programmes. Health Education Journal, 76, 648-60.

Almutairi, K, M ., Moussa M., Alajilan, A, S ., Almutairi, A. (2015). Awareness, Attitudes, and Practices Related to Coronavirus Pandemic Among Public in Saudi Arabia. Family and Community Health, 38(4), 32-340 doi: 10.1097/FCH.0000000000000082

Azlan, A,A., Hamzah, M,R., Sern, T,J., Ayub, S,H., Mohamad, E. (2020). Public knowledge, attitudes and practices towards COVID-19: A cross-sectional study in Malaysia. PLoS ONE, 15(5), e0233668. https://doi.org/10.1371/journal.pone.0233668

Bilgin, S., Kurtkulagi, O., Kahveci, G,B., Duman, T,T., Tel, B,M,A. (2020). Millennium pandemic: a review of coronavirus disease (COVID-19). Experimental Biomedical Research, ,3(2), 117-25. DOI: 10.30714/j-ebr.2020259176

Courville, T., Thompson, B.(2001). Use of structure coefficients in published multiple regression articles: $\beta$ is not enough. Educational and Psychological Measurement, 61, 229-248.

Deng, C, X. (2020). The global battle against SARS-CoV-2 and COVID-19. International .Journal of Biological Sciences, 16; 1676-1677. DOI :10.7150/ijbs.45587 Available from http://www.ijbs.com/v16p1676.htm

Erfani, A., Shahriarirad, R., Ranjbar, K., Mirahmadizadeh, A., Moghadami, M. (2020). Knowledge, Attitude and Practice toward the Novel Coronavirus (COVID-19) Outbreak: A Population-Based Survey in Iran. [Preprint].

Bull Hasan, F., Khan, M, O., Ali, M. (2018). Swine Flu: Knowledge, Attitude, and Practices 
Survey of Medical and Dental Students of Karachi. Cureus, 10(1), 1-11, e2048. DOI 10.7759/cureus.2048

Hayat, K., Rosenthal, M., Xu, S., Arshed, M., Li, P., Zhai, P. (2020). View of Pakistani Residents toward Coronavirus Disease (COVID-19) during a Rapid Outbreak: A Rapid Online Survey. International Journal of Environmental Research and Public Health, 17, 33-47; https://dx.doi.org/10.3390\%2Fijerph17103347

Hotelling, H. (1936). Relations between two sets of variates. Biometrika, 28, 312-377.

Lambert, Z, V., Durand, R, M.(1975). Some Precautions in Using Canonical Analysis. Journal of Marketing Research, 12, 468-475.

Noorbhai, H. (2020). A mathematical model to guide the re-opening of economies during the COVID-19 pandemic. Annals of medicine and surgery, 57, 5-6

Pakistan-confirms-first-two-cases-of-coronavirus COVID-19. 2020. Available online: http://covid.gov.pk/

Paul, A., Sikdar, D., Hossain, M,M., Amin, M,R., Deeba, F., Mahanta, J.(2020). Knowledge, attitudes, and practices toward the novel coronavirus among Bangladeshis: Implications for mitigation measures. PLoS ONE, 15(9), e0238492. https://doi.org/10.1371/journal.pone.0238492

Rencher A C., Christensen, W, F. (2012). Methods of Multivariate Analysis, John Wiley and Sons. INC.

Rencher, A. C. (2002). Methods of Multivariate Analysis. A Wiley-Interscience publication: 361-369

Sherry, A., Henson, R, K. (2015). Conducting and Interpreting Canonical Correlation Analysis in Personality Research: A User-Friendly Primer. Journal of Personality Assessment, 84(1), 37-48.

Shereen, M, A., Khan, S., Kazmi, A., Bashir, N., Siddique, R. (2020). COVID19 infection: Origin, transmission and characteristics of human coronaviruses. Journal of Advanced Research, 24, 91-98

Syed, F., Sibgatullah, S. (2020). Estimation of the Final Size of the COVID-19 Epidemic in Pakistan. https://doi.org/10.1101/2020.04.01.20050369 medRxiv preprint

Waris, A., Khan, A, U., Ali, M., Ali, A, Baset,A. (2020). COVID-19 outbreak: current scenario of Pakistan. [Mini Review]. New Microbes and New Infections, 35. https://doi.org/10.1016/j.nmni.2020.100681

Wang, F, S., Zhang, C. (2020). What to do next to control the 2019-nCoV epidemic? The Lancet. 394(10222), 291-393. doi: 10.1016/S0140-6736(20)30300-7

World Health Organ. E-pub: 30 March 2020. http://dx.doi.org/10.2471/BLT.20.256651

World health organization (WHO). https://www.who.int/emergencies/diseases/novelcoronavirus-2019

WHO. Coronavirus Disease 2019 (COVID-19) Situation Report-20201020.Available online:https://www.who.int/docs/default-source/coronaviruse/situationreports/20201020- weekly-epi-update-10.pdf?sfvrsn=58786643_26\&download=true

Zhong, B., Luo, W., Li, H., Zhang, Q., Liu, X., Li, W.(2020). Knowledge, attitudes and practices towards COVID- 19 among Chinese residents during the rapid rise period of the COVID-19 outbreak: a quick online cross-sectional survey. International Journal of Biological Sciences. 16, 1745-1752. https://doi.org/10.7150/ijbs.45221 PMID: 32226294 